\title{
How employee perceptions of HR practices in schools relate to employee work engagement and job performance
}

\author{
Jeske Van Beurden (D), Marc Van Veldhoven and Karina Van De Voorde \\ Department of Human Resource Studies, Tilburg University, P.O. Box 90153, NL-5000 LE Tilburg, The Netherlands \\ Author for correspondence: Jeske Van Beurden, E-mail: j.vanbeurden_1@tilburguniversity.edu
}

(Received 26 January 2021; revised 21 October 2021; accepted 22 November 2021)

\begin{abstract}
This study examines how employee perceptions of the availability and the (in)effectiveness of human resource (HR) practices in schools relate to employee performance via work engagement. Incorporating the views of 208 Dutch primary and secondary education teachers, this study's findings show that both the availability and effectiveness of HR practices are positively associated with teacher work engagement and in turn job performance. However, when employees perceive the available HR practices as effective, this has a stronger effect on teacher work engagement compared to when they only perceive the HR practices as available. Moreover, results show that HR practices that are mentioned as available, but considered ineffective, are negatively related to employee engagement and job performance. Finally, our results provide initial evidence for potential differential effects of ability-, motivation- and opportunity-enhancing HR bundles on work engagement and job performance, depending on whether the availability, ineffectiveness or effectiveness of HR practices is studied.
\end{abstract}

Keywords: Educational sector; Employee perceptions of HR practices; Human resource management; Job performance; Work engagement

Human resource management (HRM) activities, defined as all activities that are related to the management of people in organisations, have been shown to positively impact employee outcomes and organisational performance (Boxall \& Purcell, 2003; Jiang, Lepak, Hu, \& Baer, 2012). Consistent with this finding is that HR practices have been demonstrated to positively affect employee motivation and performance in the public sector (Messersmith, Patel, Lepak, \& Gould-Williams, 2011). In addition, previous research has acknowledged that HR practices play a key role in increasing performance in the education field, in particular by generating more professional and effective services (Knies, Boselie, Gould-Williams, \& Vandenabeele, 2015) and by enhancing teachers' organisational citizenship behaviour (Oplatka, 2006, 2009; Somech \& Drach-Zahavy, 2000). This is due to the fact that teachers play an important role in students' accomplishments, and teachers' competencies and efforts influence the success of schools (Rivkin, Hanushek, \& Kain, 2005). HR practices can serve as resources that stimulate teachers to contribute to the goals of the school (Vekeman, Devos, Valcke, \& Rosseel, 2018). Unfortunately, teacher shortages are a problem all over the world, as it is difficult to attract sufficiently talented and motivated people to the teaching profession. Even when schools find young, talented teachers, it is difficult to retain them, as many teachers quit because school environments fail to comply with their expectations (Runhaar, 2017). Implementing adequate HR practices can help schools attract as well as retain skilled and committed employees (Cheng, 2016).

( ) Cambridge University Press and Australian and New Zealand Academy of Management 2021. This is an Open Access article, distributed under the terms of the Creative Commons Attribution licence (https://creativecommons.org/licenses/by/4.0/), which permits unrestricted re-use, distribution, and reproduction in any medium, provided the original work is properly cited. 
Although existing research acknowledges the importance of HRM in the educational sector, research on HRM is still lagging behind compared to the profit sector (Knies et al., 2015). As a result, it remains unclear how teachers respond to HR practices and how these influence teachers' attitudes and behaviours at work. Research conducted mainly in the private sector has shown that employee perceptions of HR practices are the main predictor of employee attitudes and behaviours, which in turn affect performance (Liao, Toya, Lepak, \& Hong, 2009). Employee work engagement has proven to play a central role in fostering teacher job performance. Teachers who are engaged in their work are enthusiastic, intensely involved in work, able to work to full capacity and able to perform well (Bakker, Hakanen, Demerouti, \& Xanthopoulou, 2007). We therefore investigate the role of work engagement as a mediating mechanism in the relationship between teacher perceptions of HR practices and teacher performance. Teacher job performance refers to the extent to which an individual fulfils the prescribed requirements of the job (Griffin, Neal, \& Parker, 2007).

Schools put much effort into the implementation of HR practices such as coaching, career development, performance management, and communication and information sharing. However, the way teachers experience HR practices remains mostly unclear, which is an important oversight as teachers are the key recipients of HR practices. Recent research on employee perceptions of HR practices advocates that a distinction needs to be made between two types of employee perceptions of HR practices (Beijer, Peccei, Van Veldhoven, \& Paauwe, 2021; Boon, Den Hartog, \& Lepak, 2019; Meijerink, Beijer, \& Bos-Nehles, 2021; Van Beurden, Van de Voorde, \& Van Veldhoven, 2021): descriptive and evaluative. Descriptive perceptions concern employees' views on the HR practices in place and on the degree to which those activities are available to them (Beijer et al., 2021). Evaluative perceptions concern employees' positive or negative judgements of HR practices (Beijer et al., 2021). The main reason for distinguishing between these two types of perceptions is that the perceived availability of HR practices does not imply that employees evaluate the HR practices as satisfactory, effective or valuable (Beijer et al., 2021; Boon, Den Hartog, \& Lepak, 2019). In line with these recent developments in HR research, this study examines both descriptive (i.e., teachers' perceived availability of HR practices in schools) and evaluative conceptualisations of teacher judgements (i.e., the teachers' evaluations as to how [in] effective available HR practices are for their functioning as teachers) and argues that the impact of the mere presence of a practice can be amplified when the practice is also perceived to be effective by the teacher (Beijer et al., 2021).

As part of the attempt to gain a better understanding of the HRM-employee outcomes link, there has also been a growing focus on decomposing the full range of HR practices into three main HRM bundles by applying the ability, motivation and opportunity (AMO) framework (Appelbaum, Bailey, Berg, Kalleberg, \& Bailey, 2000). The ability-enhancing HRM bundle focuses on increasing teachers' knowledge, skills and abilities. The motivation-enhancing HRM bundle concentrates on increasing teachers' motivation and effort. The opportunity-enhancing HRM bundle focuses on increasing teachers' potential to effectively fulfil their tasks (Appelbaum et al., 2000). This study investigates the effects of the overall set of HR practices consisting of these three types of HRM bundles and of the separate ability-, motivation- and opportunity-enhancing HRM bundles. In doing so, we contribute to a growing body of literature that has found differential effects of the ability-, motivation- and opportunity-enhancing HRM bundles on employee outcomes (De Reuver, Van de Voorde, \& Kilroy, 2021; Kundu \& Gahlawat, 2018). Although this bundle approach is rarely applied in the educational literature, it provides insight into which parts of HR practices are most relevant for increasing teacher engagement and job performance.

In sum, this paper contributes to HRM literature in three ways. Firstly, this study focuses on the relationship between HRM, work engagement and job performance in the education sector; this is a research area within the context of education that is highly important yet still in its infancy compared to the profit sector (Knies et al., 2015). Secondly, this study responds to recent 
HR research by exploring employee perceptions of HRM. It distinguishes three types of employee perceptions of HR practices to create more transparency with respect to how different types of HRM perceptions relate to employee outcomes (Beijer et al., 2021; Meijerink, Beijer, \& Bos-Nehles, 2021; Van Beurden, Van de Voorde, \& Van Veldhoven, 2021): employees' perceptions of the availability of HR practices and their perceptions of the (in)effectiveness of HR practices for their work performance. Thirdly, in addition to investigating the effect of the overall set of HR practices that is relevant for teachers, this study explores the differential effects of ability-, motivation- and opportunity-enhancing HRM bundles (De Reuver, Van de Voorde, \& Kilroy, 2021; Jiang et al., 2012).

\section{A teacher perspective on HR practices in schools}

In this study, HRM, is defined as 'all those activities associated with the management of people in firms' (Boxall \& Purcell, 2003: 1). This definition highlights a combination of multiple HR practices rather than focusing on a single HR practice. Following this line of reasoning, research has indeed shown that a combination of such HR practices has a larger effect on employee attitudes and behaviours than individual HR practices (Subramony, 2009). A growing body of recent research, however, has shown the need to divide the overall set of HR practices into bundles of HR practices that enhance employees' abilities (e.g., training, coaching and career development), enhance employees' motivation (e.g., performance appraisals) or that provide the opportunity to participate (e.g., communication and information sharing) (Appelbaum et al., 2000). Earlier studies have shown that these three sets of HR practices, the ability-, motivation- and opportunity-enhancing HRM bundles, impact employee outcomes in a heterogeneous way (De Reuver, Van de Voorde, \& Kilroy, 2021; Jiang et al., 2012; Kundu \& Gahlawat, 2018; Ogbonnaya \& Messersmith, 2019). This study therefore focuses on the overall set of HR practices, but also on three HRM bundles that enhance, respectively, teacher abilities (i.e., coaching and career development), teacher motivation (i.e., performance management) and teacher opportunities (i.e., communication and information sharing) (Boselie, Dietz, \& Boon, 2005).

The strategic HRM process model offers an explanation as to why HRM is expected to influence employees' attitudes and behaviours and subsequently performance. It describes the process from the development and implementation of HRM policies and practices to their perception by teachers and how they in turn influence employee outcomes (Wright \& Nishii, 2007). This process model distinguishes between intended HR practices (the HRM policies and activities designed by school management), actual or implemented HR practices (the HR practices implemented by team leaders) and perceived HR practices (the way in which teachers perceive the actual HR practices) (Wright \& Nishii, 2007). In order to achieve the desired effects of HRM, employees, as key recipients of HRM policies and activities, need to experience and evaluate HR practices based on whether they contribute to their job performance (Browning \& Edgar, 2004). In this study, we specifically focus on the latter part of the SHRM process model, that is, employee perceptions of HR practices in relation to employee attitudes and behaviours (Wright \& Nishii, 2007).

Although there is a substantial increase in studies investigating employee perceptions of HR practices, there is still a lack of clarity about this construct (Beijer et al., 2021; Boon, Den Hartog, \& Lepak, 2019; Meijerink, Beijer, \& Bos-Nehles, 2021; Van Beurden, Van de Voorde, \& Van Veldhoven, 2021). This arises from the lack of transparency and clarity regarding conceptualisations of employee perceptions of HR practices. That is, studies investigating employee perceptions of HR practices include different types of conceptualisations, such as the availability of HR practices, the use of HR practices, the satisfaction with HR practices or their effectiveness, or include a mixture of different conceptualisations in one measure (Van Beurden, Van de Voorde, \& Van Veldhoven, 2021). In order to clarify the construct of HR practices, recent studies advocate to distinguish between descriptive and evaluative conceptualisations of perceived HRM, and they 
argue that different types of perceptions may have different effects on employee outcomes (Beijer et al., 2021; Boon, Den Hartog, \& Lepak, 2019; Meijerink, Beijer, \& Bos-Nehles, 2021; Van Beurden, Van de Voorde, \& Van Veldhoven, 2021). In light of this, the current study explores teacher perceptions of HRM by differentiating between descriptive and evaluative types of HRM perceptions.

Descriptive perceptions of HRM investigated concern the presence or availability of HR practices as perceived by teachers. This refers to the teachers' perceptions regarding the HR practices that are offered to them (Boon, Den Hartog, Boselie, \& Paauwe, 2011; Den Hartog, Boon, Verburg, \& Croon, 2013). For example, this refers to whether the teacher has coaching and career development opportunities, has performance appraisal conversations with their supervisor, or receives information about school policies and procedures. Evaluative perceptions of HRM concern the employees' subjective experiences with HR practices (Beijer et al., 2021). Different types of evaluative perceptions of HRM can be distinguished, such as the satisfaction with, fairness of and effectiveness of HR practices (Van Beurden, Van de Voorde, \& Van Veldhoven, 2021). The current study includes teachers' perceptions of the (in)effectiveness of HR practices with respect to teachers' fulfilling their job role. We focus on this type of evaluative perceptions of HRM because research on HR practices' contribution to school performance is likely to benefit especially from positive teacher perceptions regarding availability as well as effectiveness of HR practices (Runhaar, 2017). Thus, effectiveness perceptions are defined as teachers' perceptions of the extent to which HR practices enable them to function well as teachers. The effectiveness of HR practices refers, for example, to the degree to which a teacher has perceived the performance appraisal conversations as contributing to their job performance. An example of perceived ineffective HR practices refers, for example, to the degree to which a teacher has perceived performance appraisal conversations as not contributing to their job performance or even being harmful to it.

\section{The mediating role of teachers' work engagement}

Following previous research, we argue that HR practices can be viewed as job resources that help employees achieve work-related goals by providing them with necessary skills, motivation and opportunities to do so (Conway, Fu, Monks, Alfes, \& Bailey, 2016; Shen, Benson, \& Huang, 2014). The defining characteristic of job resources is that they are physical, psychological, social or organisational aspects of a job that facilitate the achievement of work goals (Demerouti, Bakker, Nachreiner, \& Schaufeli, 2001). Based on the motivational process of the JD-R model, we expect that teachers who experience HR practices as available and or effective for their functioning will show higher levels of work engagement and in turn higher levels of teacher performance (Bakker et al., 2007; Runhaar, Sanders, \& Konermann, 2013). Contrary, ineffective HR practices can be perceived as job demands that could hinder employees in the achievement of work. Employees who experience HR practices as requiring effort or skills are therefore not perceived as helpful in their job are seen as ineffective practices, which are expected to result in lower work engagement (Conway et al., 2016).

Most empirical research focusing on HR practices as job resources stems from the private sector, but shows a positive association between employee perceptions of HR practices and employee engagement (Alfes, Shantz, \& Truss, 2012; Demerouti et al., 2001). Moreover, previous research in schools has demonstrated a positive relationship between work-related resources and work engagement (Runhaar, Sanders, \& Konermann, 2013). Teachers who are engaged in work are enthusiastic and intensely involved and use their full capacity to solve problems. Moreover, they perform well and committedly strive to reach challenging goals (Bakker et al., 2007; Hakanen, Bakker, \& Schaufeli, 2006). In contrast, research has shown that when employees perceived HR practices as demands, employee engagement was lower (Conway et al., 2016).

In line with the JD-R model and the empirical evidence, we expect that teacher perceptions of the availability of the overall set of HR practices, as well as of ability-, motivation- and 
opportunity-enhancing HRM bundles, are positively related to teacher work engagement, which is in turn positively related to teacher performance. In addition, we argue that teacher perceptions of the effectiveness of the overall set of HR practices, as well as of ability-, motivationand opportunity-enhancing HRM bundles, are positively related to teacher work engagement, and subsequently to teacher performance. In line with recent research arguing that evaluative conceptualisations of HR practices are expected to have a stronger relationship with employee attitudes compared to descriptive conceptualisations (Beijer et al., 2021), we expect that teacher perceptions of the effectiveness of HR practices of the overall set of HR practices are stronger compared to when teachers perceive the HR practices only as available. Finally, we expect teacher perceptions of ineffective HR practices to be negatively related to teacher work engagement and in turn teacher performance, as teacher might perceive these HR practices as demands in their job that hinder their functioning and therefore negatively affect their engagement. Based on the theoretical and empirical argumentation above, we formulated the following hypotheses:

Hypothesis 1: Work engagement positively mediates the relationship between teacher perceptions of the overall set of (a) available and (b) effective HR practices and teacher performance.

Hypothesis 2: Work engagement negatively mediates the relationship between teacher perceptions of the overall set of ineffective HR practices and teacher performance.

Hypothesis 3: The relationship between teacher perceptions of the overall set of HR practices and work engagement is stronger when employees perceive the available HR practices also as effective.

Hypothesis 4: Work engagement positively mediates the relationship between teacher perceptions of (a) available and (b) effective ability-, motivation- and opportunity-enhancing HR practices and teacher performance.

Hypothesis 5: Work engagement negatively mediates the relationship between teacher perceptions of the ineffective ability-, motivation- and opportunity-enhancing HR practices and teacher performance.

Figure 1 below depicts the conceptual model of the study.

\section{Method}

\section{Data and sample}

The current study was conducted among primary and secondary (special) education teachers of different educational institutions in the Netherlands. Teachers were selected through a network of master students in HR studies as part of their thesis projects, under the close supervision of the authors. Convenience sampling by means of student networks is a common way to collect data in our field of study (see e.g., Biron \& van Veldhoven, 2016). In addition, combining the different student networks makes a study design possible in which data are collected from a varied and extensive sample of individual teachers (Demerouti \& Rispens, 2014). In total, 303 teachers were recruited via the following means: contacting the headmaster of a school, the head of a teacher team, or the HR manager of a school and by asking individual teachers for permission to approach their colleagues. As we were interested in teacher experiences of HR practices, we used an individual approach via the student researcher network in order to increase the heterogeneity of participants in our sample. The invited teachers then received an e-mail with a link to the digital questionnaire, a set of instructions and a guiding letter. To create a representative sample reflecting the population, employees working in primary and in secondary (special) 


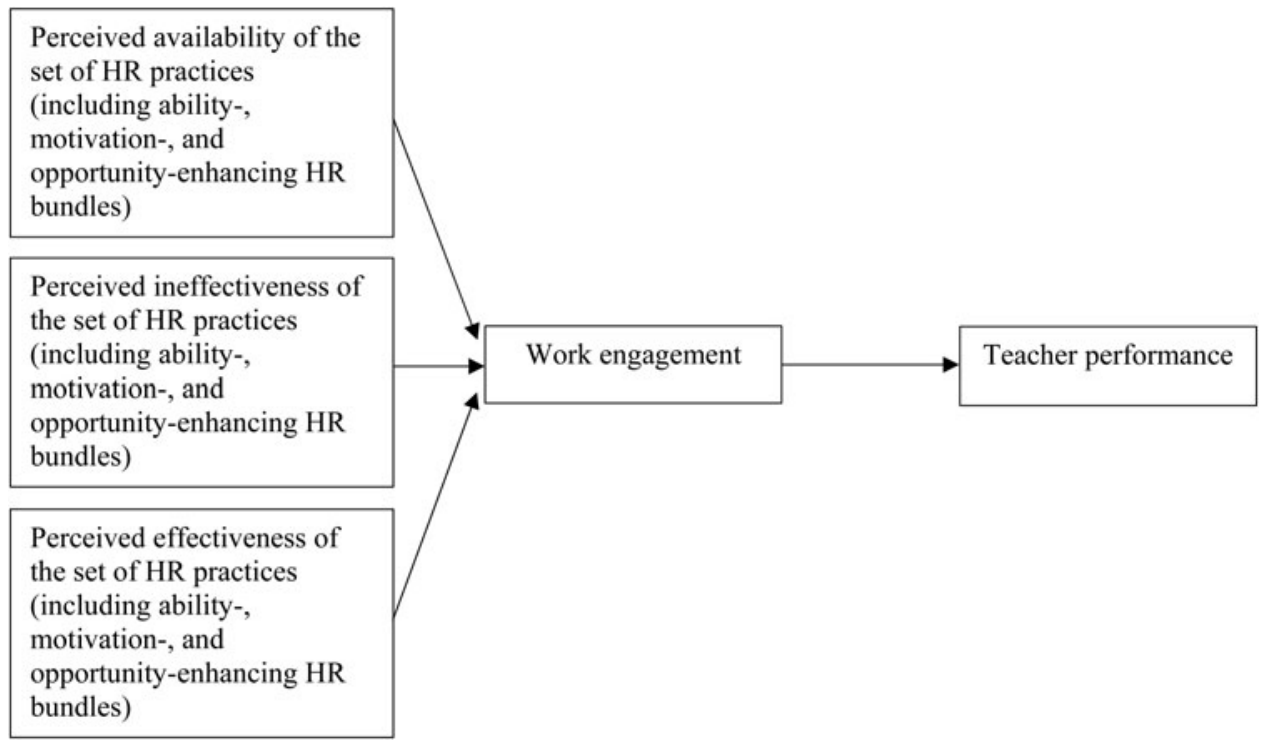

Fig. 1. Conceptual model of the study.

educational institutions, young and old employees, and male and female employees were approached to participate in the research. In addition, we underscored participant's anonymity, stressed that answers provided are their personal opinions, and highlighted that participation is voluntary. Furthermore, we informed respondents that under no circumstances their responses would be shared with members of their school. We emphasised that the data were collected for our scientific research only and that all data were stored safely. Before distributing the invitation e-mail, a pilot study was performed among three primary school and three secondary school teachers to check whether the questions were clearly formulated. No changes were made to the questions based on the results of this pilot. To increase the response rate, a reminder was sent by e-mail after one week.

In total, 208 teachers completed the questionnaire (a response rate of $69 \%$ ). Of the respondents, $76.1 \%$ were female, the average age was 41.2 years $(\mathrm{SD}=13.7)$, and $73.7 \%$ of the participants were married or cohabitating. In total, $57.6 \%$ of the respondents had children. In total, $39 \%$ of the respondents were working in primary schools, $42.9 \%$ in secondary schools and $18.1 \%$ at schools for children with special needs. Our sample reflects the Dutch labour force of teachers working in primary and secondary (special) education in terms of gender composition ( $72 \%$ of Dutch teachers working in primary and secondary [special] education are female), and average age (the average age of Dutch teachers is 43 years) (Duo, 2018).

\section{Measures}

Teacher performance was self-assessed by the teachers and was measured with a scale consisting of three items, developed and validated by Griffin, Neal, and Parker (2007). A sample item is, 'I carried out the core parts of my job well'. Items are answered on a 5-point Likert scale, ranging from 1 ('never') to 5 ('always'). The reliability of the scale was .88 .

Work engagement was measured with the Utrecht Work Engagement Scale (UWES), developed and validated by Schaufeli, Salanova, González-Romá, and Bakker (2002). The scale consisted of nine items that reflect the three underlying dimensions of work engagement (vigour, dedication and absorption). An example statement is, 'When I get up in the morning, I feel 
like going to work'. Items were answered on a 7-point scale from 1 ('never') to 7 ('always'). The item 'I can hardly detach from my work' was deleted as the corrected item-total correlation was below .30. After deleting this item, the reliability of the scale was .88.

Employee perceptions of HR practices. Several HR practices that are considered to be standard HR practices were not included in this study, with the following arguments: we decided to exclude the HR practices of recruitment and selection from our study as most individual teachers in the Netherlands are typically not directly involved in recruitment and selection processes in their schools and are therefore unlikely to have an accurate perception of this HR practices (Den Hartog et al., 2013). We also excluded items measuring workplace learning, job design and rewards, because we found too little variation in the availability of these HR practices between and within schools. In the Netherlands, pay levels in the education sector are largely determined by a collective bargaining agreement, therefore the availability of rewards is considered low (Piening, Baluch, \& Ridder, 2014). In addition, in Dutch primary and secondary education, workplace learning is common as part of a teacher's job and is therefore considered high (CAOP, 2018). Finally, teachers report relatively positively on the design of their jobs in terms of control, variety and challenging work (Bakker et al., 2007; Hakanen, Bakker, \& Schaufeli, 2006).

We adapted items measuring the perceived availability of HRM from Boon et al. (2011) and Veld, Paauwe, and Boselie (2010) in order to match our HRM item content with the school context and with previous literature on perceived HRM. The total set of HR practices was measured with nine items and included the following HR practices: coaching and career development (i.e., ability-enhancing HRM bundle), performance management (i.e., motivation-enhancing HRM bundle), and communication and information sharing (i.e., opportunity-enhancing HRM bundle). The availability of HR ( $0=$ not available, $1=$ available) was assessed using dichotomous indicators to ascertain as objectively as possible whether employees perceived that the activity was available or not (Bal, Kooij, \& De Jong, 2013). An example item of availability of HR practices was: 'My performance is periodically assessed by my supervisor'. A follow-up question asked the teachers to evaluate the practices according to how these HR practices affect their functioning in work. Evaluations ranged from 1 (a very negative effect) to 5 (a very positive effect). An example item of perceived effectiveness of HR practices was: 'How is the periodical assessment of your performance by your supervisor affecting your functioning at work?'.

We constructed three variables per respondent including (1) the number of available HR practices, (2) the number of available but ineffective HR practices, and (3) the number of available and effective HR practices. We did this by counting the number of available, available but ineffective, and available and effective reported HR practices (nine items in total) per respondent. In order to determine the cut-off point for ineffective versus effective scores, we used the answer range, for which 1,2, and 3 were taken as ineffective score, as respondents reported a negative or neutral score for the perceived effectiveness, and the scores 4 and 5 were taken as effective HR practice score for each HR practice item. The same method was also applied to the A, M and O bundles, with three items each per bundle.

A confirmatory factor analysis was performed using Mplus (version 8.3) and the WLSMV estimator to examine the validity of the availability of HR practices. In order to evaluate model fit, we followed the recommendation by $\mathrm{Hu}$ and Bentler (1998) to use multiple fit indices, including the Tucker-Lewis Index (TLI) and the Comparative Fit Index (CFI), for which values of .90 are acceptable and .95 or higher indicate a good fit. In addition, we used the Root Mean Square Error of Approximation (RMSEA) and the Standardised Root Mean Square Residual (SRMR), for which values of .08 or lower indicate an acceptable fit and below .05 indicate a good fit (Hu \& Bentler, 1998). The availability of the overall set of HR practices, in which the ability-, motivation- and opportunity-enhancing HRM bundles were used as the first order factor and the overall set of HR practices as second order, showed sufficient model fit $(\mathrm{CFI}=.998$, $\mathrm{TLI}=.997, \mathrm{RMSEA}=.030, \mathrm{SRMR}=.068)$. We used the Kuder and Richardson Formula 20 
(KR20) to check the internal consistency of the availability of HRM measures as these contain dichotomous items (Kuder \& Richardson, 1937). The value KR20 of the availability of overall set of HR practices was .73 and shows that the scale is reliable. In addition, KR20 of the availability of ability-, motivation- and opportunity-enhancing HRM bundles were $.513, .840$ and .630 , respectively. The values for ability- and opportunity-enhancing HRM bundles were relatively low but are still deemed acceptable for applications at the sample level (Salvucci, Walter, Conley, Fink, \& Saba, 1997). The full wording of the items, factor structure and factor loadings can be found in Appendix A.

Control variables. We controlled for teacher gender $(0=$ male, $1=$ female $)$, type of school $(1=$ primary [special] education, $2=$ secondary [special] education) and teacher tenure (in years). Previous research has shown that the gender and tenure of employees affect employee engagement as well as performance (Kidder, 2002; Ng \& Feldman, 2010). In addition, the type of school could affect teacher performance, as primary school teachers teach every subject to the same group of pupils whereas secondary education teachers usually teach one subject to different groups of pupils (Betoret, 2009).

\section{Common method and common source bias}

This study used self-reported data derived from a single questionnaire. We believe that selfreported data are appropriate and valuable for research on individuals' perceptions and experiences with HRM. However, this form of data collection has its drawbacks (Lee, Benoit-Bryan, \& Johnson, 2012). The self-reported data, and in particular self-rated performance, might be prone to common method bias and social desirability bias (Podsakoff, MacKenzie, Lee, \& Podsakoff, 2003). In order to reduce these biases, we performed the following actions. Firstly, we conducted a Harman's one-factor test (Podsakoff et al., 2003) to examine whether the concepts captured different constructs. A factor analysis was conducted where all the items measuring the key constructs were set to load on a single factor. This factor accounted for only $36.15 \%$ of the variance, which is below $50 \%$ and suggested that common method bias was not a serious concern in our data. Secondly, we used measures with established psychometric properties when possible and we based all scales on existing validated scales. Thirdly, anonymity was guaranteed, and only teachers who were willing to participate voluntarily filled out the questionnaire (Podsakoff et al., 2003).

\section{Analysis}

We used the MacKinnon, Fairchild, and Fritz (2007) guidelines for assessing mediation. The requirements we used for testing the hypotheses on mediation concern a statistically significant relation between (a) the independent variable (employee perceptions of HR practices) and the mediator variable (work engagement), and (b) between the mediator variable (work engagement) and the dependent variable (job performance) (MacKinnon, Fairchild, \& Fritz, 2007). To test the hypotheses, we used the Hayes PROCESS macro in SPSS (Hayes, 2013). The significance of the effects was determined by comparing the probability level $(p)$ at a significance level of .05 (two-tailed testing). The SPSS macro included 95\% bias-corrected confidence intervals for the indirect effect using 5,000 bootstrap samples. When the interval does not include zero, the indirect effect is considered to be significant. We used model 4 (Hayes, 2013) to test our hypotheses, with teacher performance as the criterion variable, teacher perceptions of HR practices as the predictor variables in separate analyses, work engagement as a mediator and the control variables included as covariates. When testing the separate HR bundles, we controlled for the other HR bundles of the same measure (i.e., when testing available ability-enhancing $\mathrm{HR}$ practices, we controlled for the available motivation- and opportunity-enhancing HR practices). 


\section{Results}

Table 1 reports the means, standard deviations and correlations for main study variables ${ }^{1}$. The overall set of available and effective HR practices correlate positively with work engagement $(r=.197, p<.01$, and $r=.295, p<.01$, respectively) and negatively with the control variable type of school ( $r=-.206, p<.01$, and $r=-.196, p<.01$ respectively). The overall set of ineffective HR practices correlates negatively with work engagement $(r=-.182, p<.01)$. Work engagement correlates positively with teacher performance $(r=.181, p<.01)$.

Table 2 reports the results of the regression analyses using Hayes' PROCESS macro for the total set of HR practices. Firstly, we tested whether work engagement positively mediates the relationship between teacher perceptions of the overall set of (a) available and (b) effective HR practices and teacher performance (Hypothesis 1). In support of Hypothesis 1, results show that work engagement positively mediates the overall set of (a) available and (b) effective HR practices and teacher performance $(B=.051, \mathrm{LL}=.012, \mathrm{UL}=.105 ; B=.072, \mathrm{LL}=.026, \mathrm{UL}=.134$, see Table 2$)$.

Secondly, we tested whether work engagement negatively mediates the relationship between teacher perceptions of the overall set of ineffective HR practices and teacher performance. Results indeed show that work engagement negatively mediates this relationship $(B=-.037$, $\mathrm{LL}=-.081, \mathrm{UL}=-.004$, see Table 2), supporting Hypothesis 2.

Thirdly, we expected that the relationship between teacher perceptions of the overall set of HR practices and work engagement is stronger when employees perceive the available HR practices also as effective. Results show the relationship between effective HR practices and work engagement is indeed stronger compared to the relationship between available HR practices and work engagement $(\beta=.308, p<.01$ and $\beta=.225, p<.01$, respectively). In addition, findings show that the relationship between teacher perceptions of the overall set of HR practices and work engagement was significantly different from the relationship between teachers' perceptions of effective HR practices and work engagement at the $90 \%$ confidence interval. In particular, results show no overlap between the lower-level confidence interval of effectiveness of HR practices $(\mathrm{LL}=.273)$, and the higher-level confidence interval of available HR practices $(\mathrm{UL}=.267)$ at the $90 \%$ confidence interval, providing marginal support for Hypothesis 3.

Next, we tested whether work engagement positively mediates the relationship between teacher perceptions of (a) the available and (b) effective ability-, motivation- and opportunity-enhancing HR practices and teacher performance (Hypothesis 4). In addition, we analysed whether work engagement negatively mediates the relationship between teacher perceptions of the ineffective ability-, motivation- and opportunity-enhancing HR practices and teacher performance (Hypothesis 5). The results show that work engagement partially mediates the relationship between the availability of the ability-enhancing HRM bundle $(B=.048, \mathrm{LL}=.007, \mathrm{UL}=.100$; see Table 3) and teacher performance and between the (a) available and (b) effective opportunity-enhancing HRM bundle $(B=.050, \mathrm{LL}=.007, \mathrm{UL}=.105 ; B=.047, \mathrm{LL}=.011$, $\mathrm{UL}=.197$; see Tables 3 and 4 respectively) and teacher performance, providing partial support for Hypothesis 4. Furthermore, findings show that work engagement negatively mediates the relationship between ineffective motivation-enhancing $\mathrm{HR}$ practices and teacher performance $(B=-.039, \mathrm{LL}=-.084, \mathrm{UL}=-.004$, see Table 5$)$. Therefore, we partially accept Hypothesis 5. These results show that the HRM bundles relate to teacher performance in a heterogeneous way. Finally, the substantiveness of the relationships between the different HR measures and work engagement is reflected by the variance explained by the perceptions of HR practices measures, ranging from 8 to $15 \%$, which is comparable with existing research studying the relationship between HRM and work engagement (Alfes, Shantz, \& Truss, 2012).

\footnotetext{
${ }^{1}$ For reader convenience we do not report the correlations for the separate HR bundles. The correlation matrix of the perceptions of available, ineffective and effective HR practices for ability-, motivation- and opportunity-enhancing HR practice are available upon request by the first author.
} 
Table 1. Descriptives and correlation matrix

\begin{tabular}{|c|c|c|c|c|c|c|c|c|}
\hline & Mean (SD) & 1 & 2 & 3 & 4 & 5 & 6 & 7 \\
\hline 1. Female ${ }^{a}$ & $.761(.428)$ & & & & & & & \\
\hline 2. Secondary education ${ }^{\mathrm{b}}$ & $1.468(.500)$ & $-.368^{\star \star}$ & & & & & & \\
\hline 3. Tenure (years) & $15.890(12.317)$ & $-.201^{\star \star}$ & $.152^{\star}$ & & & & & \\
\hline 4. Available HR practices & $5.563(2.325)$ & .002 & $-.206^{\star \star}$ & -.066 & & & & \\
\hline 5. Ineffective HR practices & $2.332(1.988)$ & -.118 & .034 & .111 & $.182^{\star \star}$ & & & \\
\hline 6. Effective HR practices & $3.231(2.771)$ & .087 & $-.196^{\star \star}$ & -.135 & $.709^{\star \star}$ & $-.565^{\star \star}$ & & \\
\hline 7. Work engagement & $5.606(.870)$ & $.228^{\star \star}$ & -.122 & -.073 & $.197^{\star \star}$ & $-.182^{\star \star}$ & $.295^{\star *}$ & \\
\hline 8. Teacher performance & $4.050(.612)$ & .007 & $.160^{\star}$ & -.098 & -.009 & -.034 & .017 & $.181^{\star \star}$ \\
\hline
\end{tabular}

Note. ${ }^{* *} p<.01 ;{ }^{\star} p<.05$

${ }^{\mathrm{a}} 0=$ male, $1=$ female.

${ }^{b_{1}}=$ primary (special) education, 2 = secondary (special) education. 
Table 2. Regression results for available, ineffectiveness and effectiveness of HR practices

\begin{tabular}{|c|c|c|c|c|c|c|}
\hline & \multicolumn{3}{|c|}{ Work engagement } & \multicolumn{3}{|c|}{ Job performance } \\
\hline & $\beta$ & SE & $R^{2}$ & $\beta$ & SE & $R^{2}$ \\
\hline \multicolumn{7}{|l|}{ Model 1} \\
\hline Constant & $4.330^{\star \star *}$ & .448 & .104 & $2.816^{\star \star}$ & .382 & .101 \\
\hline Available HR practices & $.225^{\star \star}$ & .026 & & -.020 & .050 & \\
\hline Female & $.227^{\star \star}$ & .151 & & .022 & .019 & \\
\hline Secondary education & -.006 & .131 & & $.234^{\star \star}$ & .108 & \\
\hline Tenure & -.012 & .005 & & -.114 & .004 & \\
\hline \multirow[t]{2}{*}{ Work engagement } & & & & $.229^{\star \star}$ & .050 & \\
\hline & & & B & $\mathrm{LL}$ & UL & \\
\hline \multicolumn{3}{|c|}{$\begin{array}{l}\text { Total effect of available HR practices on job } \\
\text { performance }\end{array}$} & .008 & -.029 & .046 & \\
\hline \multicolumn{3}{|c|}{$\begin{array}{l}\text { Indirect effect of work engagement on job } \\
\text { performance }\end{array}$} & $.051^{\star}$ & .012 & .105 & \\
\hline \multicolumn{7}{|l|}{ Model 2} \\
\hline Constant & $5.257^{\star \star}$ & .408 & .083 & $2.762^{\star \star}$ & .384 & .101 \\
\hline Ineffectiveness HR practices & $-.164^{\star}$ & .030 & & .018 & .021 & \\
\hline Female & $.187^{\star}$ & .153 & & .026 & .108 & \\
\hline Secondary education & -.062 & .130 & & $.238^{\star \star}$ & .090 & \\
\hline Tenure & -.008 & .005 & & -.115 & .004 & \\
\hline \multirow[t]{2}{*}{ Work engagement } & & & & $.228^{\star \star}$ & .050 & \\
\hline & & & B & $\mathrm{LL}$ & UL & \\
\hline \multicolumn{3}{|c|}{$\begin{array}{l}\text { Total effect of ineffectiveness of HR practices on job } \\
\text { performance }\end{array}$} & -.006 & -.048 & .036 & \\
\hline \multicolumn{3}{|c|}{$\begin{array}{l}\text { Indirect effect of work engagement on job } \\
\text { performance }\end{array}$} & $-.037^{\star}$ & -.081 & -.004 & \\
\hline \multicolumn{7}{|l|}{ Model 3} \\
\hline Constant & $4.536^{\star \star}$ & .398 & .147 & $2.790^{\star \star}$ & .369 & .102 \\
\hline Effectiveness HR practices & $.308^{\star \star}$ & .021 & & -.031 & .016 & \\
\hline Female & $.207^{\star \star}$ & .147 & & .023 & .108 & \\
\hline Secondary education & -.005 & .127 & & $.233^{\star \star}$ & .091 & \\
\hline Tenure & .011 & .005 & & -.116 & .004 & \\
\hline \multirow{2}{*}{\multicolumn{3}{|c|}{ Work engagement }} & & $.234^{\star \star}$ & .052 & \\
\hline & & & $\mathrm{B}$ & $\mathrm{LL}$ & UL & \\
\hline \multicolumn{3}{|c|}{$\begin{array}{l}\text { Total effect of effectiveness of HR practices on job } \\
\text { performance }\end{array}$} & .009 & -.022 & .040 & \\
\hline \multicolumn{3}{|c|}{ Indirect effect of work engagement on job performance } & $.072^{\star}$ & .026 & .134 & \\
\hline
\end{tabular}

Note. ${ }^{* *} p<.01 .{ }^{*} p<.05$. Standardised regression coefficients are reported. $\mathrm{SE}=$ standard error, 5,000 bootstrap samples. 
Table 3. Regression results for available AMO HR practices

\begin{tabular}{|c|c|c|c|}
\hline Predictor & $\beta$ & SE & $R^{2}$ \\
\hline \multicolumn{4}{|l|}{ Model 1 - work engagement $F(6,192)=5.164^{\star \star}$} \\
\hline Constant & $2.140^{\star \star}$ & .838 & .139 \\
\hline Available ability-enhancing HR practices & $.194^{\star}$ & .067 & \\
\hline Available motivation-enhancing HR practices & -.049 & .052 & \\
\hline Available opportunity-enhancing HR practices & $.200^{\star *}$ & .073 & \\
\hline Female & $.221^{\star \star}$ & .154 & \\
\hline Secondary education & .042 & .133 & \\
\hline Tenure & .009 & .005 & \\
\hline \multicolumn{4}{|l|}{ Model 2 - teacher performance $F(7,191)=4.646^{\star}$} \\
\hline Constant & $2.744^{\star \star}$ & .592 & .146 \\
\hline Work engagement & $.248^{\star \star}$ & .050 & \\
\hline Available ability-enhancing HR practices & $-.255^{\star \star}$ & .048 & \\
\hline Available motivation-enhancing HR practices & .125 & .036 & \\
\hline Available opportunity-enhancing HR practices & .094 & .052 & \\
\hline Female & .073 & .109 & \\
\hline Secondary education & $.200^{\star \star}$ & .092 & \\
\hline Tenure & $-.190^{\star \star}$ & .00 & \\
\hline \multicolumn{4}{|c|}{ Indirect effect of work engagement on teacher performance } \\
\hline Independent variable & B & $\mathrm{LL}$ & UL \\
\hline Available ability-enhancing HR practices & $.048^{\star}$ & .007 & .100 \\
\hline Available motivation-enhancing HR practices & -.012 & -.051 & .028 \\
\hline Available opportunity-enhancing HR practices & $.050^{\star}$ & .007 & .105 \\
\hline \multicolumn{4}{|l|}{ Total effect of HR practices on teacher performance } \\
\hline Independent variable & B & $\mathrm{LL}$ & UL \\
\hline Available ability-enhancing HR practices & $-.118^{\star}$ & -.215 & -.022 \\
\hline Available motivation-enhancing HR practices & .056 & -.018 & .129 \\
\hline Available opportunity-enhancing HR practices & .099 & -.004 & .201 \\
\hline
\end{tabular}

Note. ${ }^{\star \star} p<.01 .{ }^{\star} p<.05$. SE $=$ standard error, 5,000 bootstrap samples. Standardised regression coefficients are reported.

\section{Discussion}

Our findings highlight that in line with the JD-R model (Demerouti et al., 2001) work engagement acts as a mediator in the relationship between teacher perceptions of available, ineffective and effective HR practices and teacher performance. In order to positively affect work engagement and in turn teacher performance, teachers need to experience HRM as available and effective. These findings align with previous research arguing that HR practices can provide employees with the necessary skills, motivation and opportunities to achieve their work-related goals (Conway et al., 2016). Following the motivational process of the JD-R model, these practices can therefore be seen as job resources which enhance employee work engagement and in turn their job performance (Bakker et al., 2007; Runhaar, Sanders, \& Konermann, 2013). Furthermore, our findings support the argument by previous studies that the perceived 
Table 4. Regression results for effective AMO HR practices

\begin{tabular}{|c|c|c|c|}
\hline Predictor & $\beta$ & SE & $R^{2}$ \\
\hline \multicolumn{4}{|l|}{ Model 1 - work engagement $F(6,192)=5.744^{\star \star}$} \\
\hline Constant & $4.480^{\star *}$ & .404 & .152 \\
\hline Effectiveness of ability-enhancing HR practices & .140 & .071 & \\
\hline Effectiveness of motivation-enhancing HR practices & .069 & .054 & \\
\hline Effectiveness of opportunity-enhancing HR practices & $.200^{\star \star}$ & .050 & \\
\hline Female & $.208^{\star \star}$ & .148 & \\
\hline Secondary education & .008 & .130 & \\
\hline Tenure & .018 & .005 & \\
\hline \multicolumn{4}{|l|}{ Model 2 - teacher performance $F(7,191)=3.641^{\star \star}$} \\
\hline Constant & $2.843^{\star \star}$ & .369 & .118 \\
\hline Work engagement & $.236^{\star \star}$ & .051 & \\
\hline Effectiveness of ability-enhancing HR practices & -.156 & .051 & \\
\hline Effectiveness of motivation-enhancing HR practices & .043 & .038 & \\
\hline Effectiveness of opportunity-enhancing HR practices & .050 & .036 & \\
\hline Female & .026 & .107 & \\
\hline Secondary education & $.211^{\star \star}$ & .092 & \\
\hline Tenure & $-.146^{\star}$ & .004 & \\
\hline \multicolumn{4}{|l|}{ Indirect effect of work engagement on teacher performance } \\
\hline Independent variable & $\mathrm{B}$ & $\mathrm{LL}$ & UL \\
\hline Effectiveness of ability-enhancing HR practices & .033 & -.005 & .078 \\
\hline Effectiveness of motivation-enhancing HR practices & .016 & -.020 & .056 \\
\hline Effectiveness of opportunity-enhancing HR practices & $.047^{\star}$ & .011 & .097 \\
\hline Total effect of HR practices on teacher performance & B & $\mathrm{LL}$ & UL \\
\hline \multicolumn{4}{|l|}{ Independent variable } \\
\hline Effectiveness of ability-enhancing HR practices & -.074 & -.176 & .027 \\
\hline Effectiveness of motivation-enhancing HR practices & .028 & -.049 & .105 \\
\hline Effectiveness of opportunity-enhancing HR practices & .046 & -.026 & .118 \\
\hline
\end{tabular}

Note. ${ }^{\star \star} p<.01 .{ }^{\star} p<.05 . \mathrm{SE}=$ standard error, 5,000 bootstrap samples. Standardised regression coefficients are reported.

effectiveness of HR practices, that is, an evaluative conceptualisation of employee perceptions of HR practices, has a stronger relationship with employee attitudes compared to the availability of HR practices, that is, a descriptive conceptualisation (Beijer et al., 2021). In addition, results of this study show that teacher perceptions of ineffective HR practices are negatively related to teacher work engagement and in turn job performance. These findings are in line with empirical evidence which found a negative relationship between the lack of motivational resources and employee outcomes such as work engagement (Conway et al., 2016; Demerouti et al., 2001).

Related to the ability-, motivation- and opportunity-enhancing HRM bundles, the results of this study reveal that differences exist in how these HRM bundles are related to teacher outcomes. The results confirming Hypotheses 1 and 2 when regarding all practices combined are confirmed differentially for the bundles based on the AMO framework, for example, depending on whether 
Table 5. Regression results for ineffective AMO HR practices

\begin{tabular}{|c|c|c|c|}
\hline Predictor & $\beta$ & SE & $R^{2}$ \\
\hline \multicolumn{4}{|l|}{ Model 1 - work engagement $F(6,192)=3.335^{\star \star}$} \\
\hline Constant & $5.266^{\star *}$ & .408 & .094 \\
\hline Ineffectiveness of ability-enhancing HR practices & .040 & .094 & \\
\hline Ineffectiveness of motivation-enhancing HR practices & $-.166^{\star}$ & .056 & \\
\hline Ineffectiveness of opportunity-enhancing HR practices & -.078 & .055 & \\
\hline Female & $.169^{\star}$ & .155 & \\
\hline Secondary education & -.055 & .130 & \\
\hline Tenure & .002 & .005 & \\
\hline \multicolumn{4}{|l|}{ Model 2 - teacher performance $F(7,191)=3.382^{\star}$} \\
\hline Constant & $2.716^{\star \star}$ & .386 & .110 \\
\hline Work engagement & $.239 * \star$ & .050 & \\
\hline Ineffectiveness of ability-enhancing HR practices & -.076 & .065 & \\
\hline Ineffectiveness of motivation-enhancing HR practices & .080 & .039 & \\
\hline Ineffectiveness of opportunity-enhancing HR practices & -.008 & .038 & \\
\hline Female & .040 & .109 & \\
\hline Secondary education & $.233^{\star \star}$ & .090 & \\
\hline Tenure & -.123 & .004 & \\
\hline \multicolumn{4}{|l|}{ Indirect effect of work engagement on teacher performance } \\
\hline Independent variable & B & $\mathrm{LL}$ & UL \\
\hline Ineffectiveness of ability-enhancing HR practices & .010 & -.020 & .042 \\
\hline Ineffectiveness of motivation-enhancing HR practices & $-.039^{\star}$ & -.084 & -.004 \\
\hline Ineffectiveness of opportunity-enhancing HR practices & -.019 & -.059 & .012 \\
\hline \multicolumn{4}{|l|}{ Total effect of HR practices on teacher performance } \\
\hline Independent variable & $\mathrm{B}$ & $\mathrm{LL}$ & UL \\
\hline Ineffectiveness of ability-enhancing HR practices & -.061 & -.193 & .070 \\
\hline Ineffectiveness of motivation-enhancing HR practices & .021 & -.057 & .010 \\
\hline Ineffectiveness of opportunity-enhancing HR practices & -.014 & -.091 & .063 \\
\hline
\end{tabular}

Note. ${ }^{* *} p<.01 .{ }^{\star} p<.05 . \mathrm{SE}=$ standard error, 5,000 bootstrap samples. Standardised regression coefficients are reported.

we study available, ineffective or effective $\mathrm{HR}$ practices we find different $\mathrm{A}, \mathrm{M}$ and $\mathrm{O}$ bundles to be significant. This would seem to point towards the importance of differentiating between AMO bundles in research using the employee perspective on HRM (Jiang et al., 2012). In particular, work engagement mediates the relationship between availability of the ability- and opportunity-enhancing HR bundles and teacher performance (Vermeeren, 2017). For the motivation-enhancing HR bundle, findings show that work engagement mediates the relationship between ineffective motivation-enhancing HR practices and teacher performance, in such a way that this bundle is negatively associated with work engagement, and that work engagement is positively associated with teacher performance. This result highlights that ineffective motivation-enhancing HR practices can be harmful to teacher outcomes (Van Waeyenberg, Peccei, \& Decramer, 2020). Finally, work engagement mediates the relationship between the 
effective opportunity-enhancing HR bundle and teacher performance. Our findings align with recent empirical studies that have also found the opportunity-enhancing HR bundle to be more important for employee outcomes compared to the ability- and motivation-enhancing HR bundle (De Reuver, Van de Voorde, \& Kilroy, 2021; Kundu \& Gahlawat, 2018; Ogbonnaya \& Messersmith, 2019; Vermeeren, 2017). We found the opportunity-enhancing HR bundle to be the only bundle of the three AMO-bundles to witness effects both when measured via availability only and when measured via availability coupled with effectiveness.

Finally, we found that availability of ability-enhancing HR practices has a direct negative effect on teacher performance. This is the only direct effect worth mentioning next to the aforementioned indirect effects that were all substantiated. A possible explanation for this finding is that Dutch primary and secondary education teachers might experience training and development practices as not directly contributing to the core tasks of their job, which is teaching their pupils. More specifically, investing time and effort in training and development might divert from spending hours on the main tasks of teaching students (Grant, Christianson, \& Price, 2007). Therefore, although the availability of training and career development opportunities engage teachers in their work, it might detract them from performing their job well. It is important to acknowledge that such negative direct and positive mediated effects can co-exist, and that is not a matter of either/or, but aiming to let the positive mediated effects outweigh the direct negative effects.

\section{Limitations and suggestions for future research}

Although the present study has its strengths, it is not without limitations. Firstly, our measurements were collected and from the same source at one point in time and were self-reported. Therefore, common method bias and common source bias may sway the results (Podsakoff et al., 2003). However, the results of our one-factor test revealed that common method bias is not likely to be a serious concern in our data. In addition, we used validated scales where possible and collected data anonymously and voluntarily to attempt to reduce common source bias. In addition, because we used a cross-sectional research design, we cannot draw conclusions about causal effects.

Secondly, the scale we used to measure the availability and (in)effectiveness of HRM has its limitations. We formulated a follow-up question based on the perceived availability of HR practices. However, if employees report that they do not perceive a certain HR practice as available, we do not know whether they miss this practice to help them to perform well. This requires a different kind of approach than inquiring about perceived effectiveness or ineffectiveness. There is a need to develop the conceptualisation of assessing the perceived effectiveness of HR practices further, in a way that employees who do not perceive practices as available, are also asked to report whether they feel they are missing out on certain practices (Van Beurden, Van de Voorde, \& Van Veldhoven, 2021).

Finally, teacher performance was self-assessed in this study, which could be a limitation because employees tend to overrate themselves (De Cuyper \& De Witte, 2011). However, we believe that self-reported measures of performance are justifiable in this study for two reasons. Firstly, research has shown that, in particular, less-skilled workers tend to overrate themselves in terms of in-role performance (Davis, Mazmanian, Fordis, Van Harrison, Thorpe, \& Perrier, 2006). Our sample included highly educated workers, however, so performance bias may have been limited. Secondly, performance in the education sector is a complex, multidimensional construct (Knies \& Leisink, 2014). Therefore, future research could incorporate different evaluation dimensions and perspectives in order to investigate individual performance (De Cuyper \& De Witte, 2011).

Given the findings of our study, we encourage future studies to further investigate teacher perceptions of HR practices and to clearly identify the type(s) of perception they aim to examine (Beijer et al., 2021; Van Beurden, Van de Voorde, \& Van Veldhoven, 2021). Researchers will 
need to specify the type(s) of perception of HRM they use and why. For example, a descriptive type of HRM perception could provide greater insight into the validity of claims as to offered HR practices by (line) management, while an evaluative type of HRM perception could better be used to study the extent to which HR practices contribute to individual performance improvement (Jiang et al., 2012; Wright \& Nishii, 2007). In addition, our findings highlight differential relationships for the ability-, motivation- and opportunity-enhancing HRM bundles with teacherrelevant outcomes. We therefore suggest further exploration of how such differences in HR practices affect other important teacher outcomes such as teacher health well-being (e.g., stressors and strain) and teacher happiness (e.g., job satisfaction and organisational commitment).

\section{Implications}

The present study has some important practical implications for management in the education sector. In particular, our study shows that the effectiveness of the overall set of HR practices is more strongly associated with teachers' work engagement compared to the availability of HR practices, which in turn is positively associated with their performance. To benefit from HR practices, school management should pay attention to how teachers perceive the HR practices in terms of their effectiveness in helping them function well (Abbott \& De Cieri, 2008). It might be that two teachers interpret the same available HRM practices differently and that these HR practices might therefore be seen as idiosyncratic. For this reason, it is important to not focus only on what teachers perceive in terms of the availability of HR practices. Rather, school management will gain more insight if they also examine how HR practices are experienced by the teachers. In particular, they should discuss the extent to which teachers perceive the set of HR practices as available and effective.

Furthermore, results show that different HRM bundles have different relationships with teacher work engagement. More specifically, in order to enhance teacher work engagement and in turn teacher performance, school management should provide training and development opportunities, and implement communication and information activities that teachers perceive as effective in helping them function in their roles. In addition, school management can enhance teacher work engagement and job performance by focusing on how teachers experience the performance management practices in their school, specifically to prevent such practices from being perceived as ineffective.

\section{Conclusion}

This study adds to existing research about teacher perceptions of HR practices and their relationship with teacher work engagement and job performance, in the context of the Dutch education sector. By investigating how teachers perceptions of available, ineffective and effective HR practices affect teacher work engagement and teacher performance, our findings underline the importance of differentiating these types of HRM perceptions, as they have differential relationships with teacher outcomes. Our findings further suggest that offering ability-enhancing HR practices, providing effective opportunity-enhancing $\mathrm{HR}$ practices and preventing motivational-enhancing HR practices from being perceived as ineffective is beneficial for improving teacher engagement and job performance.

\section{References}

Abbott, J., \& De Cieri, H. (2008). Influences on the provision of work-life benefits: Management and employee perspectives. Journal of Management \& Organization, 14(3), 303-322.

Alfes, K., Shantz, A., \& Truss, C. (2012). The link between perceived HRM practices, performance and well-being: The moderating effect of trust in the employer. Human Resource Management Journal, 22(4), 409-427. 
Appelbaum, E., Bailey, T., Berg, P., \& Kalleberg, A.. (2000). Manufacturing advantage: Why high-performance work systems pay off. Ithaca, NY: Cornell University Press.

Bakker, A. B., Hakanen, J. J., Demerouti, E., \& Xanthopoulou, D. (2007). Job resources boost work engagement, particularly when job demands are high. Journal of Educational Psychology, 99(2), 274-284.

Bal, P. M., Kooij, D. T., \& De Jong, S. B. (2013). How do developmental and accommodative HRM enhance employee engagement and commitment? The role of psychological contract and SOC strategies. Journal of Management Studies, 50(4), 545-572.

Beijer, S., Peccei, R., Van Veldhoven, M., \& Paauwe, J. (2021). The turn to employees in the measurement of human resource practices: A critical review and proposed way forward. Human Resource Management Journal, 31(1), 1-17.

Betoret, F. D. (2009). Self-efficacy, school resources, job stressors and burnout among Spanish primary and secondary school teachers: A structural equation approach. Educational Psychology, 29(1), 45-68.

Biron, M., \& van Veldhoven, M. (2016). When control becomes a liability rather than an asset: Comparing home and office days among part-time teleworkers. Journal of Organizational Behavior, 37(8), 1317-1337.

Boon, C., Den Hartog, D. N., Boselie, P., \& Paauwe, J. (2011). The relationship between perceptions of HR practices and employee outcomes: Examining the role of person-organisation and person-job fit. The International Journal of Human Resource Management, 22(01), 138-162. doi: 10.1080/09585192.2011.538978

Boon, C., Den Hartog, D. N., \& Lepak, D. P. (2019). A systematic review of human resource management systems and their measurement. Journal of Management, 45(6), 2498-2537.

Boselie, P., Dietz, G., \& Boon, C. (2005). Commonalities and contradictions in HRM and performance research. Human Resource Management Journal, 15(3), 67-94. doi: 10.1111/j.1748-8583.2005.tb00154.x

Boxall, P., \& Purcell, J. (2003). Strategy and human resource management: Management, work and organisations. Hampshire: Palgrave MacMillan.

Browning, V., \& Edgar, F. (2004). Reactions to HRM: An employee perspective from South Africa and New Zealand. Journal of Management \& Organization, 10(2), 1-13.

CAOP. (2018). Career perspectives of teachers in the context of the job mix primary and secondary education. Available from https://www.voion.nl/media/2630/carriereperspectievenvanlerareninhetkadervandefunctiemixpoenvo.pdf (accessed 2 May 2020).

Cheng, K. T. (2016). Doing good in public schools: Examining organisational citizenship behaviour in primary school teachers. Journal of Management and Organization, 22(4), 495.

Conway, E., Fu, N., Monks, K., Alfes, K., \& Bailey, C. (2016). Demands or resources? The relationship between HR practices, employee engagement, and emotional exhaustion within a hybrid model of employment relations. Human Resource Management, 55(5), 901-917. doi: 10.1002/hrm.21691

Davis, D. A., Mazmanian, P. E., Fordis, M., Van Harrison, R. T. K. E., Thorpe, K. E., \& Perrier, L. (2006). Accuracy of physician self-assessment compared with observed measures of competence: A systematic review. JAMA, 296(9), 1094-1102.

De Cuyper, N., \& De Witte, H. (2011). The management paradox: Self-rated employability and organizational commitment and performance. Personnel Review, 40(2), 152-172.

Demerouti, E., Bakker, A. B., Nachreiner, F., \& Schaufeli, W. B. (2001). The job demands-resources model of burnout. Journal of Applied psychology, 86(3), 499.

Demerouti, E., \& Rispens, S. (2014). Improving the image of student-recruited samples: A commentary. Journal of Occupational and Organizational Psychology, 87(1), 34-41.

Den Hartog, D. N., Boon, C., Verburg, R. M., \& Croon, M. A. (2013). HRM, communication, satisfaction, and perceived performance: A cross-level test. Journal of Management, 39(6), 1637-1665.

De Reuver, R., Van de Voorde, K., \& Kilroy, S. (2021). When do bundles of high performance work systems reduce employee absenteeism? The moderating role of workload. The International Journal of Human Resource Management, 32(13), 28892909.

Dienst Uitvoering Onderwijs (DUO) (2018) Personnel in primary and secondary education. Available from: https://duo.nl/ open_onderwijsdata/databestanden/po/onderwijspersoneel/ (accessed April 10, 2020).

Grant, A. M., Christianson, M. K., \& Price, R. H. (2007). Happiness, health, or relationships? Managerial practices and employee well-being tradeoffs. Academy of Management Perspectives, 21(3), 51-63.

Griffin, M. A., Neal, A., \& Parker, S. K. (2007). A new model of work role performance: Positive behavior in uncertain and interdependent contexts. Academy of Management Journal, 50(2), 327-347.

Hakanen, J. J., Bakker, A. B., \& Schaufeli, W. B. (2006). Burnout and work engagement among teachers. Journal of School Psychology, 43(6), 495-513.

Hayes, A. F. (2013). Model templates for PROCESS for SPSS and SAS.

Hu, L. T., \& Bentler, P. M. (1998). Fit indices in covariance structure modeling: Sensitivity to underparameterized model misspecification. Psychological Methods, 3(4), 424-453.

Jiang, K., Lepak, D. P., Hu, J., \& Baer, J. C. (2012). How does human resource management influence organizational outcomes? A meta-analytic investigation of mediating mechanisms. Academy of Management Journal, 55(6), $1264-1294$.

Kidder, D. L. (2002). The influence of gender on the performance of organizational citizenship behaviors. Journal of Management, 28(5), 629-648. 
Knies, E., Boselie, P., Gould-Williams, J., \& Vandenabeele, W. (2015). Special issue of International Journal of Human Resource Management: Strategic human resource management and public sector performance, 26(3), 421-424.

Knies, E., \& Leisink, P. (2014). Linking people management and extra-role behaviour: Results of a longitudinal study. Human Resource Management Journal, 24(1), 57-76.

Kuder, G. F., \& Richardson, M. W. (1937). The theory of the estimation of test reliability. Psychometrika, 2(3), 151-160.

Kundu, S. C., \& Gahlawat, N. (2018). Ability-motivation-opportunity enhancing human resource practices and firm performance: Evidence from India. Journal of Management and Organization, 24(5), 730-747.

Lee, G., Benoit-Bryan, J., \& Johnson, T. P. (2012). Survey research in public administration: Assessing mainstream journals with a total survey error framework. Public Administration Review, 72(1), 87-97.

Liao, H., Toya, K., Lepak, D. P., \& Hong, Y. (2009). Do they see eye to eye? Management and employee perspectives of highperformance work systems and influence processes on service quality. Journal of Applied Psychology, 94(2), 371-391.

MacKinnon, D. P., Fairchild, A. J., \& Fritz, M. S. (2007). Mediation analysis. Annual Review Psychology, 58, 593-614.

Meijerink, J. G., Beijer, S. E., \& Bos-Nehles, A. C. (2021). A meta-analysis of mediating mechanisms between employee reports of human resource management and employee performance: Different pathways for descriptive and evaluative reports? The International Journal of Human Resource Management, 32(2), 394-442.

Messersmith, J. G., Patel, P. C., Lepak, D. P., \& Gould-Williams, J. S. (2011). Unlocking the black box: Exploring the link between high-performance work systems and performance. Journal of Applied Psychology, 96(6), 1105-1118.

Ng, T. W., \& Feldman, D. C. (2010). Organizational tenure and job performance. Journal of Management, 36(5), 1220-1250.

Ogbonnaya, C., \& Messersmith, J. (2019). Employee performance, well-being, and differential effects of human resource management subdimensions: Mutual gains or conflicting outcomes? Human Resource Management Journal, 29(3), 509-526.

Oplatka, I. (2006). Going beyond role expectations: Toward an understanding of the determinants and components of teacher organizational citizenship behavior. Educational Administration Quarterly, 42(3), 385-423.

Oplatka, I. (2009). Organizational citizenship behavior in teaching: The consequences for teachers, pupils, and the school. International Journal of Educational Management, 23(5), 375-389.

Piening, E. P., Baluch, A. M., \& Ridder, H. G. (2014). Mind the intended-implemented gap: Understanding employees' perceptions of HRM. Human Resource Management, 53(4), 545-567.

Podsakoff, P. M., MacKenzie, S. B., Lee, J. Y., \& Podsakoff, N. P. (2003). Common method biases in behavioral research: A critical review of the literature and recommended remedies. Journal of Applied Psychology, 88(5), 879-903.

Rivkin, S. G., Hanushek, E. A., \& Kain, J. F. (2005). Teachers, schools, and academic achievement. Econometrica, 73(2), 417-458.

Runhaar, P. (2017). How can schools and teachers benefit from human resources management? Conceptualising HRM from content and process perspectives. Educational Management Administration \& Leadership, 45(4), 639-656.

Runhaar, P., Sanders, K., \& Konermann, J. (2013). Teachers' work engagement: Considering interaction with pupils and human resources practices as job resources. Journal of Applied Social Psychology, 43(10), 2017-2030.

Salvucci, S., Walter, E., Conley, V., Fink, S., \& Saba, M. (1997). Measurement error studies at the National Center for Education Statistics.

Schaufeli, W. B., Salanova, M., González-Romá, V., \& Bakker, A. B. (2002). The measurement of engagement and burnout: A two sample confirmatory factor analytic approach. Journal of Happiness Studies, 3(1), 71-92.

Shen, J., Benson, J., \& Huang, B. (2014). High-performance work systems and teachers' work performance: The mediating role of quality of working life. Human Resource Management, 53(5), 817-833.

Somech, A., \& Drach-Zahavy, A. (2000). Understanding extra-role behavior in schools: The relationships between job satisfaction, sense of efficacy, and teachers' extra-role behavior. Teaching and Teacher Education, 16(5-6), 649-659.

Subramony, M. (2009). A meta-analytic investigation of the relationship between HRM bundles and firm performance. Human Resource Management, 48(5), 745-768.

Van Beurden, J., Van de Voorde, K., \& Van Veldhoven, M. (2021). The employee perspective on HR practices: A systematic literature review, integration, and outlook. International Journal of Human Resource Management, 32(2), $359-393$.

Van Waeyenberg, T., Peccei, R., \& Decramer, A. (2020). Performance management and teacher performance: The role of affective organizational commitment and exhaustion. The International Journal of Human Resource Management, Epub ahead of print. doi: 10.1080/09585192.2020.1754881

Vekeman, E., Devos, G., Valcke, M., \& Rosseel, Y. (2018). Principals' configuration of a bundle of human resource practices. Does it make a difference for the relationship between teachers' fit, job satisfaction and intention to move to another school? Educational Management Administration \& Leadership, 46(5), 820-840.

Veld, M., Paauwe, J., \& Boselie, P. (2010). HRM and strategic climates in hospitals: Does the message come across at the ward level? Human Resource Management Journal, 20(4), 339-356.

Vermeeren, B. (2017). Influencing public sector performance: Studying the impact of AMO-enhancing HR practices on various performance outcomes in the public sector. International Review of Administrative Sciences, 83(4), 717-737.

Wright, P. M., \& Nishii, L. H. (2007). Strategic HRM and organizational behavior: Integrating multiple levels of analysis (CAHRS Working Paper \#07-03). Ithaca, NY: Cornell University, School of Industrial and Labor Relations, Center for Advanced Human Resource Studies. http://digitalcommons.ilr.cornell.edu/cahrswp/468. 


\section{Appendix A}

Factor structure of ability-, motivation-, and opportunity-enhancing HR practices for the availability of the overall set of HR practices

\begin{tabular}{|c|c|c|c|}
\hline & \multicolumn{3}{|c|}{ Component $^{\mathrm{a}}$} \\
\hline & 1 & 2 & 3 \\
\hline My performance is periodically assessed by my supervisor. & .890 & & \\
\hline I have a periodic conversation with my supervisor about my performance. & .936 & & \\
\hline My performance goals are set by mutual agreement. & .713 & & \\
\hline I am informed about what's going on at the school. & & .862 & \\
\hline The policies and procedures within the school are communicated to me. & & .898 & \\
\hline I gain insight into the way in which decision-making within the school takes place. & & .667 & \\
\hline I am coached in the development of my knowledge and skills. & & & .829 \\
\hline I receive guidance in my career development. & & & .810 \\
\hline I have career opportunities in education. & & & .614 \\
\hline
\end{tabular}

Note. ${ }^{\mathrm{a} C o m p o n e n t} 1$ represents the motivation-enhancing HR bundle, component 2 is the opportunity-enhancing HR bundle, and component 3 the ability-enhancing HR bundle. STDYX standardization estimates are reported. An empty cell indicates a factor loading below .30 .

Cite this article: Van Beurden J, Van Veldhoven M, Van De Voorde K (2021). How employee perceptions of HR practices in schools relate to employee work engagement and job performance. Journal of Management \& Organization 1-19. https:// doi.org/10.1017/jmo.2021.66 